\title{
El legado del siglo XX \\ Los retos para la conservación del patrimonio \\ arquitectónico moderno en el Perú
}

David Rivera Gámez / Fernando Vela Cossío

Universidad Politécnica de Madrid, España

Recibido: 29 de septiembre de 2015 / Aprobado: 20 de febrero de 2016

Los criterios para la protección y la conservación de los elementos que integran lo que denominamos patrimonio cultural, descansan sobre convenciones que han ido cambiando con el tiempo y que se han vertebrado de forma diferente en cada nación. El caso del patrimonio arquitectónico y urbano del siglo XX no es diferente de los demás. Realizamos un análisis de la situación en que se encuentra la arquitectura moderna en Latinoamérica, en el Perú, y en concreto en la ciudad de Lima, aproximándonos a sus distintos estilos, al estado de conservación de estos bienes y a la manera en que ha sido percibido por ciudadanos e instituciones.

patrimonio arquitectónico del siglo XX, Movimiento Moderno en Latinoamérica, conservación y restauración del patrimonio arquitectónico

\section{The Legacy of the Twentieth Century. Challenges for the Conservation of Modern Architectural Heritage in Peru}

Criteria for protection and conservation of the elements forming part of what we call cultural heritage, lie on conventions that have changed through time, being assimilated differently in each nation. The case of architectural and urban heritage of the twentieth century is not different from others. We developed an analysis of the condition of modern architecture in Latin America, within Peru, and particularly in Lima. We will approach the different styles, the conservation condition of this kind of goods and the way it has been and it is now perceived by citizens and institutions.

architectural heritage of the twentieth century, Modern Movement in Latin America, conservation and restoration of architectural heritage 
En la mayor parte de los países europeos se ha venido haciendo un gran esfuerzo desde finales del siglo XX, para incorporar en los catálogos de patrimonio construido y edificaciones protegidas un número creciente, y muy considerable, de edificios contemporáneos importantes. La organización Docomomo (acrónimo de "Documentación y conservación de la arquitectura, los sitios y el patrimonio construido del Movimiento Moderno"), fundada en Holanda en el año 1988 y dedicada exclusivamente a la documentación y conservación de los edificios y sitios proyectados por los arquitectos vinculados al Movimiento Moderno, ha proporcionado a una parte de este importante legado de nuestro tiempo la visibilidad y la valoración que necesitaba para que pudiese ser percibido como una parte substancial del patrimonio cultural compartido universalmente y, por ende, para que pudiera ser puesto a salvo y a disposición de las generaciones venideras, algo que en un principio resultó extraordinariamente complicado a causa del carácter reciente de las obras y también, y quizás en gran medida, por el carácter impersonal, adusto y abstracto de un lenguaje arquitectónico que no gozó precisamente de gran popularidad en el último tercio del siglo pasado. Muchos otros estilos y tendencias modernas, más amables, han encontrado de forma más expedita su camino hacia los catálogos, adquiriendo una pátina histórica suficientemente sólida en menos tiempo. Este sería el caso del art nouveau de Bruselas o París, o de las obras de la Sezession en Viena, Praga o Budapest, la mayoría de ellas convertidas actualmente en monumentos de primerísima importancia y con un gran reconocimiento no solo entre los especialistas. Otras obras, procedentes del Art Déco, el Expresionismo, el Eclecticismo o el Clasicismo Moderno, se han incorporado igualmente al conjunto del patrimonio arquitectónico universal, y sus edificios son estudiados y restaurados, y cobran nueva vida ahora como monumentos.

Este proceso de patrimonialización está desarrollándose actualmente con mucha fuerza y vigor en numerosos países de Latinoamérica, en especial en aquellos que cuentan con un patrimonio contemporáneo abundante, variado y notable en calidad, con ejemplos de todas las grandes tendencias importantes del siglo XX, desde el Art Nouveau al Brutalismo. Sin embargo, el desarrollo de los criterios de catalogación y protección del patrimonio arquitectónico de la modernidad en los países latinoamericanos, presenta sus propios rasgos y desafios particulares, lo que es preciso analizar y enfrentar 
desde el estudio de las respectivas situaciones urbanas. El significado de las obras de la arquitectura moderna puede además resultar muy variable en cada país, de acuerdo al estilo y la cronología de los edificios, por las asociaciones que puedan evocar, por la identificación de una parte de la sociedad y de la opinión pública con algunas obras concretas y según el uso que se haya hecho de ellas a lo largo del tiempo.

\section{LA SITUACIÓN DEL PATRIMONIO ARQUITECTÓNICO MODERNO A COMIENZOS DEL SIGLO XXI}

Los principios de conservación y protección del patrimonio arquitectónico se asientan naturalmente en convenciones culturales que son propias de cada época y lugar. El caso del patrimonio arquitectónico del siglo XX no es diferente a los demás. El siglo XXI tendrá que definir el número y la calidad de los edificios del siglo anterior que desea preservar o convertir en patrimonio cultural; de hecho, desde finales de los años ochenta la mayoría de los países de Europa ha hecho un gran esfuerzo para incorporar a sus catálogos de edificaciones protegidas un número muy considerable de edificios "modernos" importantes, seguidos por los Estados Unidos y por los países latinoamericanos, muchos de los cuales cuentan ya con un catálogo razonable de edificios modernos protegidos. La tarea, sin embargo, no ha hecho más que empezar.

En 1991, el Consejo de Europa emitió su "Recomendación (91) 13 del Comité de Ministros a los Estados Miembros relativa a la protección del patrimonio arquitectónico del siglo XX" (Moreno de Barreda, 1999). Se trataba básicamente de la primera toma de conciencia acerca del valor y del peligro que corrían los edificios representativos de la arquitectura moderna, si bien la parte normativa del documento se limitaba a la recomendación de formar especialistas apropiados, estrategias para la identificación y estudio de este tipo de patrimonio, la elaboración de inventarios sistemáticos, el mantenimiento del uso de los edificios y la difusión y concienciación entre la ciudadanía europea. La preocupación del Consejo de Europa por el patrimonio arquitectónico moderno puede retrotraerse hasta 1985, a la 2. ${ }^{a}$ Conferencia de Ministros responsables del Patrimonio Arquitectónico, en la que se creó virtualmente el conjunto de los nuevos patrimonios, que incluye también el patrimonio arquitectónico rural o vernáculo y el patrimonio industrial. 
Esta aproximación al patrimonio moderno construido suscitó enseguida la cuestión de la representatividad en la Lista del Patrimonio Mundial de la Unesco, la World Heritage List (en adelante, WHL), creada en 1972. En el año 2004, cuando se celebró una importante reunión de especialistas sobre la representatividad de la Lista, esta contaba con 754 propiedades inscritas (muchas de ellas, conjuntos). Conforme el patrimonio arquitectónico moderno iba incorporándose y definiéndose, saliendo de la contemporaneidad para introducirse en la historia, algunas de sus manifestaciones consideradas esenciales fueron inscritas en la Lista. En 1996 se inscribieron "los sitios de la Bauhaus" (todas las construcciones de la Bauhaus en Weimar y Dessau), la Casa Schröder de Gerrit Rietveld se inscribió en el 2000 y la Casa Tugendhat de Ludwig Mies van der Rohe en el 2001 (Harboe, 2004). La ciudad de Brasilia había entrado en la lista en 1987, poco más de treinta años después de la construcción del núcleo fundamental por Oscar Niemeyer y Lúcio Costa. Desde entonces se han ido incluyendo con cuentagotas algunos edificios y conjuntos, y muchas de las intervenciones importantes en edificios modernos, como la Fábrica Van Nelle, el sanatorio de Zonnestraal, laVilla Müller o los conjuntos de Bruno Taut, fueron realizadas considerando la posible inclusión de los edificios en la Lista de la Unesco, para lo cual es preciso cumplir con unos requisitos de significatividad y autenticidad que son ciertamente discutibles. La mayoría de las obras maestras del Movimiento Moderno no aparecen en la Lista y seguirán sin estar, porque la WHL no puede ser un inventario. La aproximación al patrimonio moderno ha cambiado el enfoque desde el gran monumento o conjunto histórico a la pieza significativa escogida con más o menos arbitrariedad de entre un mar de ejemplos posibles igualmente valiosos.

Para solucionar precisamente esa cuestión hacía falta un tipo de organización totalmente diferente. Ahí está el punto de partida de Docomomo, una institución internacional con delegaciones en numerosos países y regiones del mundo. Una asociación que se ha marcado un objetivo ambicioso y quizá impracticable: proteger no solamente los edificios, sino también el planeamiento urbano y el paisajismo practicado por los arquitectos del Movimiento Moderno. 
Los objetivos de la organización se sintetizan en el denominado "Eindhoven Statement", que consta de seis puntos:

- llevar a la atención del público, de las autoridades, la profesión y la comunidad educativa la significatividad del Movimiento Moderno;

- identificar y promover el reconocimiento de obras del Movimiento Moderno, incluyendo un registro, dibujos, fotografias, archivos y otros documentos;

- impulsar el desarrollo de apropiados métodos y técnicas de conservación y difundir este conocimiento a través de las profesiones;

- oponerse a la destrucción y desfiguración de las obras significativas del Movimiento Moderno;

- identificar y atraer fondos para la documentación y la conservación;

- explorar y desarrollar el conocimiento de la arquitectura del Movimiento Moderno.

Para Docomomo, los edificios del Movimiento Moderno se encuadrarían, a grandes rasgos, en el período 1920-1970. Los criterios utilizados por la organización para incluir un edificio en sus listas de protección se basan en los utilizados por la Unesco y son muy diversos, pero todos ellos significativos e interesantes a priori. Se trata del "mérito tecnológico", el "mérito social", el "mérito artístico y estético", el "mérito canónico", el "valor referencial" y la "integridad" presente del inmueble. No es preciso que una obra concreta pueda valorarse a partir de los seis puntos, pero se considera tanto más defendible cuantos más de ellos cumple. Los procedimientos de catalogación, documentación y "puesta en valor" que utiliza Docomomo para contrarrestar el abandono y las agresiones contra el patrimonio arquitectónico del Movimiento Moderno, se basan en una metodología sistemática situada en un punto de acuerdo flexible cercano tanto al Restauro Critico (que valora el carácter y la integridad artísticas por encima de la "autenticidad" del material) como a la llamada "cultura del mantenimiento" que, a partir de los escritos teóricos de restauradores 
como Paolo Marconi, pone el énfasis en el correcto conocimiento del edificio y en la reproducción fiel de los sistemas constructivos empleados en la medida de lo posible y razonable, lo que diferencia de entrada la actitud de muchos de los defensores del patrimonio arquitectónico moderno de la esgrimida usualmente por eruditos y arquitectos con respecto al patrimonio tradicional, cuyo contenido material original ha sido siempre objeto de las más enconadas disputas y, a la inversa, cuya forma ha sido reinterpretada con una libertad que hoy consideramos abusiva.

En el año 2001, el World Heritage Centre, Icomos y Docomomo crearon un Programme on Modern Heritage destinado a la identificación y "puesta en valor" del patrimonio arquitectónico de los siglos XIX y XX. Unesco e Icomos ya se habían puesto de acuerdo en 1994 para definir una "estrategia global para una lista del patrimonio mundial equilibrada y representativa", lo que significaba prestar una atención mayor al patrimonio no elitista (vernáculo, popular), geográficamente más inclusivo y tipológicamente más amplio, además de menos localizado alrededor de personalidades geniales y obras maestras. Se consideró que precisamente este tipo de patrimonio menos reconocido era el que más en peligro se encontraba. Dejando aparte las cuestiones políticas y diplomáticas y las trivialidades inevitables de lo políticamente correcto, al menos este enfoque más abierto y crítico suponía una mayor atención hacia legados como el de la modernidad, que parecía haber perdido su agresividad arrasadora y predominante y haber menguado hasta una fragilidad superior a la de sus precedentes.

En la reunión celebrada en la sede de la Unesco en París en 2001, especialistas en arquitectura moderna como Jean-Louis Cohen, expertos en patrimonio como Francesco Bandarin y restauradores del patrimonio moderno como Hubert-Jan Henket, discutieron los problemas del patrimonio moderno con un énfasis en el siglo XX, partiendo de la cuestión de la representatividad en la WHL y perdiéndose después en asuntos como la clasificación del patrimonio (paisajes culturales, patrimonio industrial, etc.) y las estrategias de "puesta en valor" (como las fichas del Docomomo). Los representantes del Docomomo hicieron hincapié en la cuestión de la selección entre la enorme abundancia de obras de un siglo que se ha apoyado especialmente en la idea de lo colectivo, estandarizado y masificado, y también destacaron 
el papel relevante del concepto por encima de la materia, algo que sin duda desentona con las ideas al uso de la Unesco.

Un caso típico del mecanismo adoptado por las instituciones es el del compromiso de English Heritage con el patrimonio arquitectónico moderno. La institución central de la preservación en el Reino Unido recomendó la protección de setenta edificios modernos, construidos en el siglo XX, a finales de los años ochenta. Solo dieciocho de ellos fueron finalmente aceptados y protegidos, pero en 1991 English Heritage comenzó a desarrollar un programa de investigación destinado a poner en evidencia los valores y méritos históricos y artísticos de los edificios del siglo XX. Después de años de trabajo intensivo, finalmente en el año 2000 fueron catalogados trescientos edificios modernos.

En el año 2008, la celebración de la $10^{\text {th }}$ International Docomomo Conference en Rotterdam, en la exquisitamente restaurada Fábrica Van Nelle, marcó un momento de recapitulación muy importante, en el que se pudo comprobar que, a los veinte años de la fundación de Docomomo, la protección, revalorización y restauración de la arquitectura del Movimiento Moderno seguía su curso por sí sola, haciendo prácticamente prescindible la propia existencia de la institución, que seguirá funcionando sin duda como foro de debate y como registro más o menos oficial de lo que ocurre con el patrimonio ingente y aún amenazado que cae bajo su jurisdicción disciplinar. Esta décima conferencia internacional, además, supuso un cambio en el peso específico político y teórico de la institución, constatando su creciente mundialización y su paralela descentralización. El reconocimiento de ese patrimonio arquitectónico del Movimiento Moderno es actualmente una realidad global.

\section{LA ARQUITECTURA MODERNA EN AMÉRICA LATINA}

La arquitectura del Movimiento Moderno en Latinoamérica disfrutó en un primer momento de una imagen progresista y fuertemente ligada a los mitos nacionalistas: las ciudades universitarias modernas construidas en Caracas, México D.F., Bogotá, Guatemala, La Habana o Panamá, algunas de ellas incluidas hace poco por la Unesco en la WHL, son un ejemplo prístino de 
la búsqueda del optimismo y la renovación nacional a través de la imagen arquitectónica del Movimiento Moderno, como lo son también los centros cívicos diseñados para Sao Paulo, la Ciudad de Guatemala o Lima, o para enclaves más pequeños como Santa Rosa en Argentina, aunque el paradigma evidente de esta tendencia es la apresurada creación de Brasilia a partir de 1957.

El proceso de patrimonialización de la arquitectura moderna latinoamericana ha pasado, sin embargo, por muy distintas circunstancias. En algunos casos, como los de Guatemala o Panamá, la arquitectura moderna parece haber sido completamente olvidada en los catálogos monumentales; en otros casos nos encontramos con una serie de obras importantes convenientemente protegidas. Más raramente puede evidenciarse una cierta conciencia pública acerca de la importancia patrimonial de la arquitectura del siglo XX. Veamos ahora algunos ejemplos representativos.

El primero lo encontramos, naturalmente, en el Brasil. La obra de Oscar Niemeyer (1907-2012) destaca en América Latina por ser la más reconocida y apreciada con verdadera amplitud. Si bien la configuración ideada para la ciudad de Brasilia por Lúcio Costa (1902-1998) no ha contado con la misma estima, los edificios de Niemeyer para la nueva capital se convirtieron enseguida en verdaderos símbolos nacionales y su patrimonialización ha sido muy rápida. Brasilia fue inscrita en el año 1987 en la WHL. Constituyó el primer ejemplo de conjunto urbano del Movimiento Moderno en obtener este honor, atendiendo a sus valores de representatividad y significatividad cultural, además de sus logros estéticos específicos.

México constituye nuestra segunda referencia. Ha conseguido articular un paradigma arquitectónico moderno de gran solidez y calidad, y no ha descuidado tampoco la cuestión de la protección legal de las obras más importantes. Al igual que las construcciones ligeras e imaginativas del español Félix Candela (1910-1997), completamente ausentes de la pesadez e inexpresividad que lastran una gran parte de la arquitectura moderna convencional, las casas proyectadas por Luis Barragán (1902-1988) en México D.F. y en Guadalajara han ido obteniendo, desde comienzos del siglo XXI, el estatus de monumento. La propia casa-estudio del arquitecto (1948) fue incluida por la Unesco en la Lista del Patrimonio Mundial en el año 2004, siendo la aportación de Barragán una de las versiones 
menos doctrinarias e internacionales de la arquitectura del Movimiento Moderno. Por otro lado, las casas funcionalistas que Juan O'Gorman (19051982) proyectó para Diego Rivera y Frida Kahlo en 1931, constituyen un ejemplo temprano de la presencia intelectual del Movimiento Moderno en México, al tiempo que muestran una influencia evidente de las casas-estudio racionalistas diseñadas por Le Corbusier. Mediante un decreto especial, estas casas fueron declaradas Patrimonio Artístico de la Nación en 1978. El propio Juan O'Gorman, muralista como Diego Rivera además de arquitecto, es el autor del edificio más llamativo del nuevo campus de la Universidad Nacional Autónoma de México: la Biblioteca Central (1950), un singular ejemplo de síntesis entre el bloque prismático funcionalista y la decoración de inspiración precolombina, perteneciente ya a la etapa en que O'Gorman renegaba de sus inicios doctrinarios funcionalistas. El campus de la UNAM fue incluido como conjunto en la WHL por la Unesco en el año 2007, siendo probablemente el ejemplo mejor conservado y mantenido de ciudad universitaria latinoamericana concebida según los criterios del Movimiento Moderno prácticamente a modo de conjunto demostrativo.

En el caso de la Argentina, la toma de posición quizá ha resultado algo más tardía, pero sin embargo ha demostrado ser una decidida valedora intelectual de la arquitectura del Movimiento Moderno. La Casa del Puente de Mar del Plata (1943), de Amancio Williams (1913-1989), abandonada y en estado ruinoso, fue declarada Monumento Nacional en 1989 y se halla en la actualidad en proceso de restauración, mientras que la única obra de Le Corbusier (1887-1965) en América Latina, la Casa Curutchet (1949), cuidadosamente restaurada y declarada Monumento Nacional en 1987, es actualmente la sede del Colegio de Arquitectos de la ciudad de La Plata. Buenos Aires no carece de obras funcionalistas de importancia media, pero mantuvo durante la parte central del siglo XX un sesgo favorable al Art Déco. Quizá por ello no es sino hasta la época del Brutalismo cuando la capital argentina comenzó a producir iconos arquitectónicos indiscutibles. El Banco de Londres (1960), proyectado por Clorindo Testa (1923-2013) en colaboración con el estudio SEPRA, es probablemente el más importante de todos ellos, y, a pesar de su juventud, fue declarado Monumento Histórico Nacional en 1999. 
En Colombia también hay numerosos casos de edificios modernos protegidos en la actualidad, entre ellos ciertas obras representativas de Leopoldo Rother (1894-1978) y Rogelio Salmona (1929-2007), así como el famoso Hotel Tequendama de Santa Fe de Bogotá, construido por Camilo Cuéllar, Gabriel Serrano y José Gómez con asesoría norteamericana en 1950-51 y ampliado en 1967-70. Salmona se formó con Le Corbusier y regresó a Colombia en 1958, pero su visión de la arquitectura, a la vez abstracta y expresiva, con predominancia de la fábrica de ladrillo trabajada con cuidado, se halla más bien en la línea de Alvar Aalto (1898-1976). El conjunto Torres del Parque (1965-1970) fue declarado Bien de Interés Cultural Nacional ya en 1995, mientras que el Hotel Tequendama lo fue en el año 2002.

En La Habana, donde el Movimiento Moderno cuenta con una representación espectacular, la producción local ha sido especialmente bien catalogada y estudiada por la sección cubana de Docomomo, aun cuando la protección de las obras se ve dificultada por circunstancias económicas y políticas obvias. El Club Tropicana (1951), obra del pionero funcionalista Max Borges (19182009), atestigua una libertad de inventiva en el trabajo con las cáscaras de hormigón que acercan el experimentalismo cubano a los juegos formales brasileños. El prestigio de este edificio, mantenido en uso y publicitado por el régimen comunista, ha favorecido su declaración como Monumento Nacional en el año 2002.

Venezuela no fundó su propia rama del Docomomo hasta el año 2010, y ello solamente a raíz de la reunión internacional celebrada ese año en México D.F. (11. a Asamblea General de Docomomo). Una vez fundada, la asociación apenas ha podido hacer otra cosa que constatar el grave estado de deterioro en que se halla un gran número de edificios ya históricos y la dificultad de presentarlos a los ojos del público como elementos artísticos o de valor. No obstante, la Ciudad Universitaria de Caracas (desde 1940), cuyo plan maestro se debe a Carlos Raúl Villanueva (1900-1975), fue incluida por la Unesco en la WHL en el año 2000, siendo por lo tanto uno de los pocos ejemplos de la arquitectura del Movimiento Moderno que se benefician de tal reconocimiento, aun cuando la conservación y el mantenimiento de este conjunto no son especialmente buenos. 


\section{EL CASO PERUANO}

El Perú es una de las grandes referencias de la América Latina en lo que respecta al Patrimonio Cultural. Con una superficie de $1200000 \mathrm{~km}^{2}$ y treinta millones de habitantes, se encuentra en un proceso de fuerte crecimiento y desarrollo, habiendo alcanzado un PIB cercano a los 203 mil millones de dólares, según datos del Banco Mundial correspondientes a 2014. El país disfruta de un legado excepcional en el que puede leerse el largo y complejo proceso histórico que ha conformado el Perú mestizo de nuestros días. Un patrimonio reconocido por la Unesco desde hace más de tres décadas, en declaraciones tan señaladas como la del Santuario Histórico del Machu Picchu (1983), la ciudad del Cusco (1983), el sitio arqueológico de Chavín (1985), el Parque Nacional del Huascarán (1985), la zona arqueológica de Chan-Chan (1986), el Parque Nacional del Manú (1987), el Centro Histórico de Lima (1991), el Parque Nacional del río Abiseo (1992), las líneas y geoglifos de Nazca y Jumana, el centro histórico de Arequipa (2000), la ciudad sagrada de Caral-Supe (2009) y el Qhapaq Nan o camino inca (2014). Además, en la lista indicativa de la Unesco se encuentran las propuestas de declaración del centro histórico de Trujillo, el yacimiento de Pachacámac, el centro histórico de Cajamarca, el lago Titicaca, el complejo arqueológico de Kuélap y el astronómico de Chankillo. El arte textil de Taquile, la Danza de las Tijeras de Ayacucho, la Huaconada de Mito (Junín), los cantos Eshuva de los Huachipaeri, la peregrinación al santuario de Qoyllurit'i en Sinakara (Cusco) y los conocimientos y técnicas para la renovación del puente Q'eswachaka sobre el río Apurímac, son, en el ámbito del patrimonio inmaterial, los elementos inscritos por el Perú en el Patrimonio Mundial, y constituyen una pequeña muestra del inmenso legado intangible que aún conserva el Perú del siglo XXI. Con un valiosísimo y muy reconocido patrimonio arqueológico, resultado del extenso desarrollo de las grandes civilizaciones agrícolas que desde el décimo milenio antes de Cristo poblaron la región, el Perú conserva también elementos verdaderamente extraordinarios en ámbitos como el patrimonio del paisaje y la arquitectura tradicional, que se reparten por todo el país. El numeroso conjunto de ciudades históricas que el país conserva, ofrece un patrimonio arquitectónico y urbano riquísimo y heterogéneo, en el que conviven las huellas de las primitivas culturas prehispánicas con muestras extraordinarias de la arquitectura colonial de los siglos XVI al XVIII, y con 
elementos muy destacables del patrimonio industrial y de la arquitectura de los siglos XIX y XX (Vela Cossío, 2014, pp. 44-45).

Su capital, la ciudad de Lima, ha sido una de las metrópolis sudamericanas que ha experimentado un crecimiento importante a lo largo del siglo XX, impulsada por el notable progreso económico del país. La apertura del Canal de Panamá en 1914 daba al Perú una conexión directa con Europa y contribuía a sentar los cimientos de su importante desarrollo como gran centro comercial y exportador a través de su histórico puerto: El Callao. El crecimiento de la economía peruana durante el periodo de entreguerras y, sobre todo, después de la Segunda Guerra Mundial (1939-1945) y de la Guerra de Corea (1950-1953), hicieron de Lima un espacio ideal para el desarrollo de importantes experiencias urbanas y arquitectónicas, muy representativas de la modernidad latinoamericana.

$\mathrm{La}$ arquitectura peruana, después de la importante extensión de los estilos académicos de influencia europea durante la segunda mitad del siglo XIX -sobre todo desde el final de la Guerra del Pacífico (1879-1883) - y tras el posterior desarrollo del Eclecticismo, el Art Nouveau y el Art Déco, se verá señalada en las décadas siguientes por la extensión del llamado estilo Neocolonial, impulsado con mucha fuerza por autores extranjeros llegados al Perú, como el polaco Ricardo de Jaxa Malachowski Kulisicz (1887-1972) o el francés Claude Sahut Laurent (1883-1932), y también por peruanos como Emilio Harth-Terré (1899-1983), que hicieron de Lima una capital de apariencia tradicional y muy monumentalizada a principios de los años cuarenta. El Palacio Arzobispal (Malachowski, 1916), el Palacio de Gobierno (Sahut, 1926; Malachowski, 1936-38), la plaza San Martín con sus edificios (1926-1940), la embajada argentina (Martín S. Noel, 1940), la Municipalidad de Lima (Harth-Terré y Álvarez Calderón, 1944) o la de Miraflores (Luis Miró-Quesada Garland, 1944) constituyen ejemplos muy representativos de este periodo y de este modo de intervención en la ciudad histórica. El historiador hispano-chileno Leopoldo Castedo (1915-1999) ha considerado que, durante esta etapa, el "Perú fue víctima, tal vez más que ningún otro país iberoamericano, de la moda neocolonial. Los resultados se multiplicaron por el coeficiente de un apoyo oficial irrestricto y con abundantes caudales" (Castedo, 1970, pp. 301-302). Para Castedo, Lima siguió el camino de una 
reconstrucción artificiosa, basada en "casas californianas" y verdaderos pastiches del barroco histórico, lo que añade valor al empeño de los arquitectos que abrieron el paso a una modernidad que el autor reconoce en la buena construcción privada del distrito de Miraflores, a la que enseguida nos vamos a referir, y en algunos edificios de la Ciudad Universitaria.

Tal como recoge la excelente Guía de arquitectura y paisaje de Lima y El Callao (Bonilla di Tolla, 2009) -a la que remitimos en todo lo relativo a las particularidades, en las que no podemos detenernos, de los edificios limeños que se mencionan en este artículo-, la ciudad se había extendido entre 1900 y 1940 mediante el trazado de grandes ejes como la avenida Brasil, que partiendo desde la plaza Bolognesi alcanzaba Pueblo Libre, o la avenida Augusto Leguía (hoy, Arequipa) y el Paseo de la República, que conducían a Miraflores, reconstruido casi por completo después de la Guerra del Pacífico, al igual que Barranco y Chorrillos. El distrito se reorganizará por completo a partir de 1940 con la configuración del óvalo de Miraflores y del Parque Central, situados en el encuentro de la avenida Arequipa con José Pardo, Diagonal, Larco y Ricardo Palma, conformándose uno de los centros neurálgicos más importantes de la Lima contemporánea.

En ese contexto de gran desarrollo urbano, los acontecimientos políticos y los grandes cambios económicos y sociales de la posguerra, como el golpe militar de Manuel Arturo Odría Amoretti (1896-1974), que tuvo lugar el 27 de octubre de 1948, los inmediatos gobiernos de la Junta Militar (19481950) y los posteriores, ya constitucionales, del mismo Odría entre 1950 y 1956, transformarán definitivamente las estructuras del país. Durante todo este periodo, el impulso de las grandes obras públicas y de las infraestructuras, el fomento de la industrialización y la construcción de grandes edificios al servicio de la Administración, facilitarán la extensión de la arquitectura moderna, a la cual también contribuyeron desde luego la creciente sensibilidad de la clase profesional y los cambios en la propia enseñanza de la arquitectura. Para Ramón Gutiérrez, "la formación en 1947 de la Agrupación Espacio, tuvo influencia en los cambios de la enseñanza de la arquitectura en la Escuela Nacional de Ingenieros, aunque el acertado rumbo conceptual significó al comienzo el descenso en el oficio profesional" (Gutiérrez, 2002, p. 628). 
Durante los años cuarenta y cincuenta Lima verá levantarse un número muy significativo de edificios modernos, entre los que se han conservado obras de gran interés, de autores tan señalados en la historia de la arquitectura moderna del Perú como el ya mencionado Luis Miró-Quesada Garland (1914-1994), autor del libro Espacio en el tiempo (Lima, 1945), uno de los textos más importantes para comprender el desarrollo de la modernidad en el país andino. Su Casa Wiracocha (1947) refleja fielmente el espíritu de su pensamiento. El suizo Teodoro Cron (Basilea, 1925), formado en el Politécnico de Zurich y llegado al Perú en 1948, levanta los apartamentos del 390 de la calle Roma (1949). Pero la década de los cincuenta es seguramente la más importante para el desarrollo de la arquitectura moderna en el Perú. Mario Bianco, llegado al país en 1947, trabaja en la Facultad de Arquitectura de la Universidad Nacional de Ingeniería (1951-1953). Manuel Villarán Freire (1926-2007) proyecta el edificio Guzmán Blanco (1952). Enrique Seoane Ros (1915-1980) desarrolla, entre otros proyectos, el antiguo Ministerio de Educación (avenida Abancay, 1951-1956), una de las obras más emblemáticas de los gobiernos de Odría, el edificio Ostolaza (avenida Tacna, 1951-1953), que recibió el Premio Chavín, el edificio Diagonal (calle Olaya, 1952-1954), de planta triangular ligeramente convexa, y el edificio residencial Limatambo (avenida José Pardo, 19531954). Guillermo Payet proyecta el Ministerio de Hacienda (avenida Abancay, 1952-1953). José Álvarez Calderón construye la Compañía de Seguros Atlas (1953-1955), proyecto en el que colabora Walter Weberhofer (1923-2002), que es también autor del Club Esmeralda (Santa María, 1956) y del inconcluso conjunto del cine Tauro (jirón Washington, 1958). Y a finales de la década, Fernando de Osma diseña uno de los mejores edificios modernos de Miraflores: el edificio El Pacífico (avenida José Pardo esquina con Diagonal, 1958), un interesante conjunto cuyos pisos inferiores están destinados a actividades comerciales y recreativas (sala cinematográfica), el tercero se reserva a estacionamiento y la torre, de dos cuerpos, es de uso residencial. Ese mismo año, Alberto Menacho diseña el edificio Neptuno, en el malecón San Martín de Ancón, una de las zonas del área metropolitana del norte de Lima con mayor densidad de arquitectura en los años cincuenta y sesenta. 

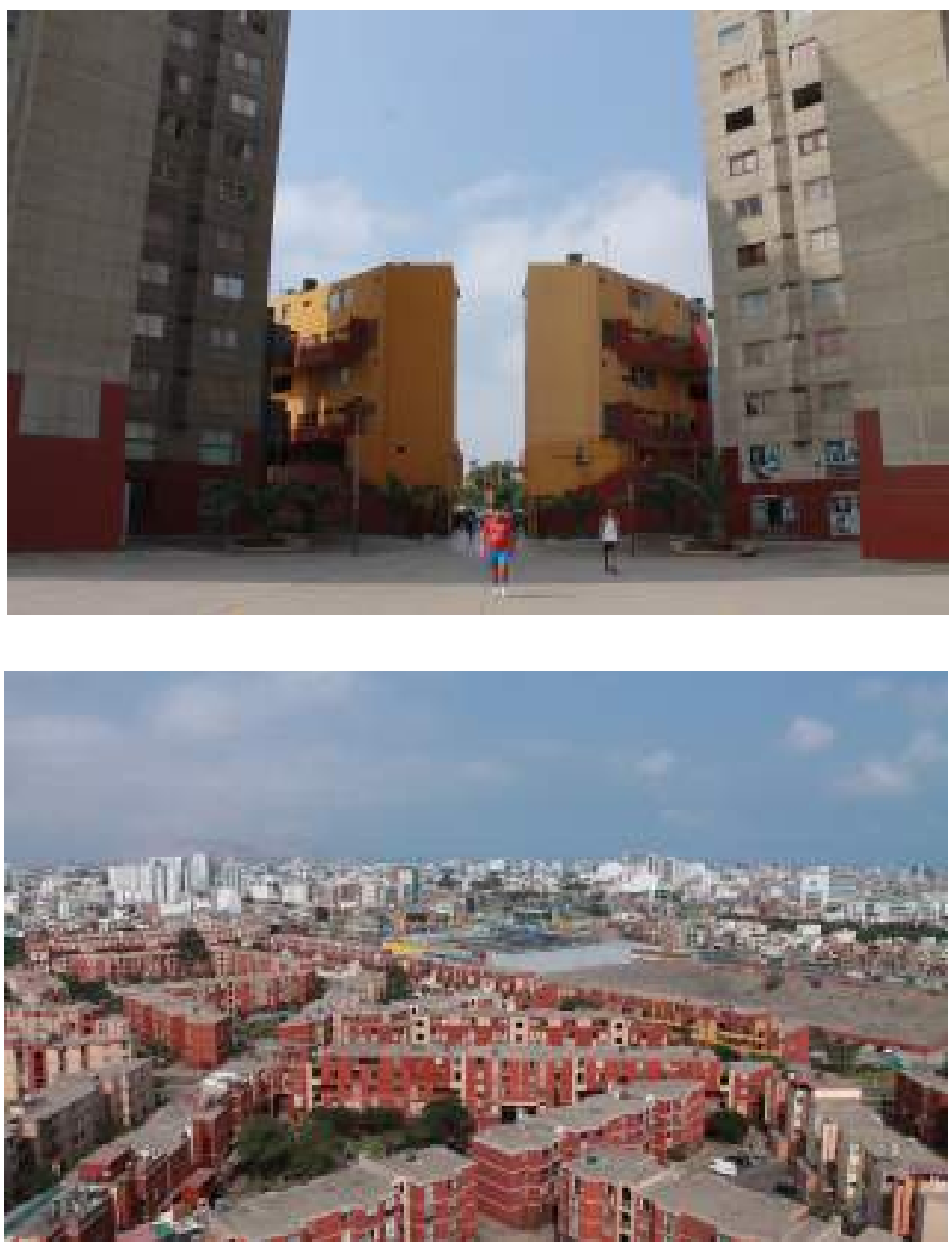

Figura 1.

Limatambo

Fuente: Fotografías de Gonzalo Cortés 
Los años sesenta corresponden precisamente a los gobiernos del arquitecto Fernando Belaunde Terry (1912-2002), que prestó especial atención a la vivienda social a través de la Junta Nacional de la Vivienda. En este ámbito hay que destacar especialmente los Proyectos Experimentales de Viviendas (PREVI), nacidos en el periodo de Belaunde (1966), pero que no se construirían, sin embargo, hasta la década siguiente, de 1972 a 1976.

Hay que recordar que Fernando Belaunde, especialista en urbanismo formado en los Estados Unidos, fue además el fundador de la revista El Arquitecto Peruano, que se publicó desde agosto de 1937. En palabras de Miguel Cruchaga, la gravitación de la revista:

[...] fue muy grande y sirvió para introducir los principales temas de la arquitectura, el planeamiento urbano, las políticas de vivienda, la preservación del patrimonio monumental y la valoración de la arqueología. Se publicó durante 40 años, hasta mediados de 1977. Fue una tribuna abierta y plural con la que colaboraron los principales arquitectos del medio. Su objetivo central fue difundir y prestigiar la arquitectura realizada en el Perú. (Cruchaga, 2004)

En el final de la década de los sesenta Lima asistirá al desarrollo del Brutalismo. Ramón Gutiérrez ya ha señalado cómo la tardía extensión de la arquitectura moderna en el Perú -en parte, consecuencia de la larga extensión, hasta bien entrados los cincuenta, de la moda neocolonial- entronca con el desarrollo de las propuestas brutalistas, que se extienden en el país andino sobre un importante conjunto de obras públicas que incorporan "sofisticada tecnología norteamericana de aluminio, vidrios reflejantes, cristales templados y otras potencialidades que señalan la constante distancia entre las posibilidades del país y las inversiones de la arquitectura emergente" (Gutiérrez, 2002, p. 629).

Así, entre 1966 y 1970 se levanta el Centro Cívico de Lima (Paseo de la República), obra de Adolfo Córdova, Miguel Llona, José García Bryce, Simón Ortiz, Jorge Páez, Ricardo Pérez León y Carlos Williams. El Centro Cívico, resultado de un concurso realizado en el periodo de Belaunde, señaló, en palabras de Ramón Gutiérrez, "un salto cualitativo en la temática arquitectónica peruana, sobre todo en el cuidado tecnológico de su realización y obviamente en su expresividad. Sin embargo, significó un enorme fiasco en lo que hace a sus calidades urbanas y espaciales" (Gutiérrez, 2002, p. 630). También durante esta etapa, Ricardo J. Malachowski Benavides (1922-2011) 

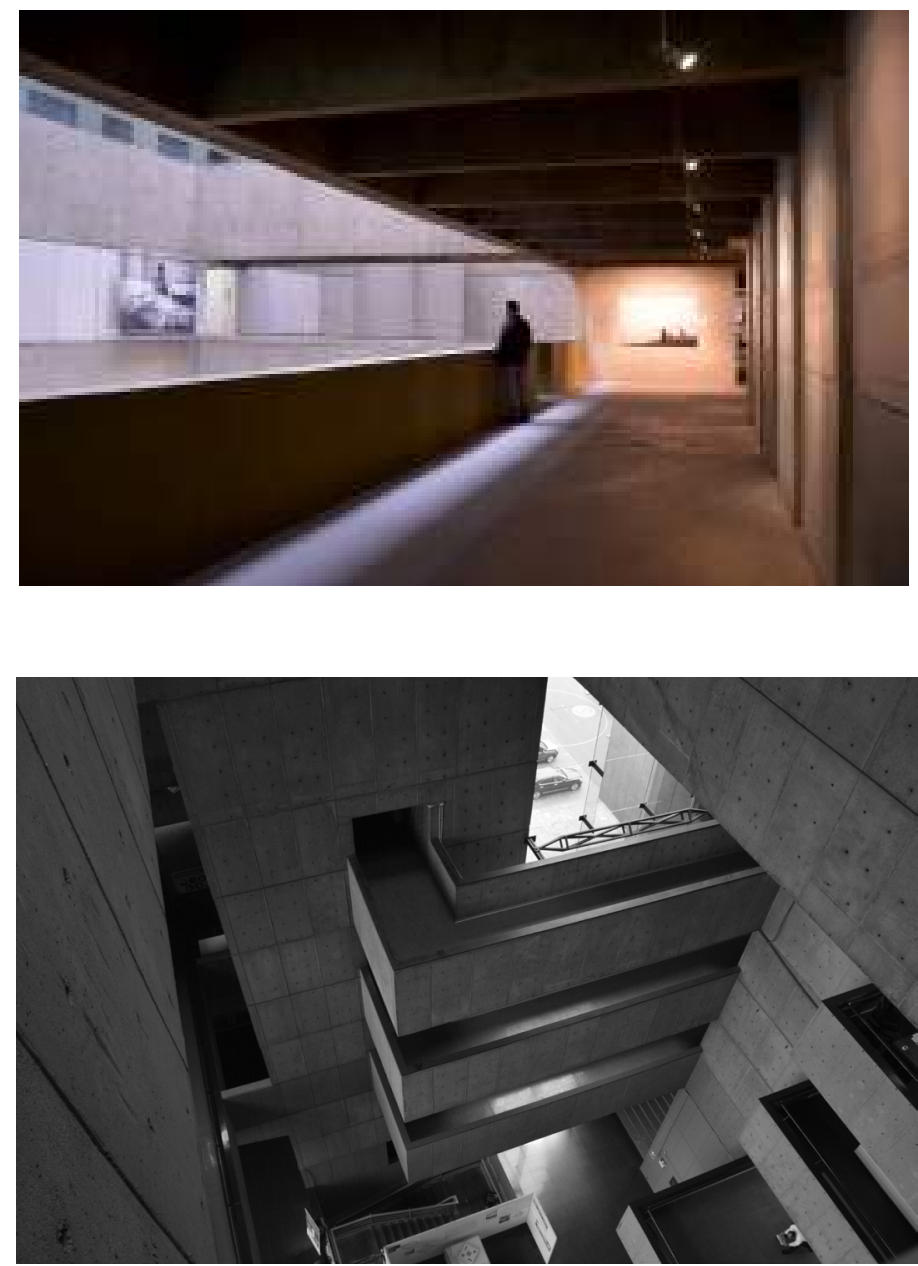

Figura 2.

Museo de la Nación

Fuente: Fotografías de Vanessa Briceño

y el norteamericano Edward Durell Stone (1902-1978) proyectan en colaboración, junto al Centro Cívico, el Hotel Sheraton y el centro de convenciones. Igualmente, Daniel Arana Ríos y Walter Weberhofer 
diseñan el edificio PetroPerú (Paseo de la República, 1969-1970), y Miguel Cruchaga, Miguel Rodrigo Mazuré y Emilio Soyer terminan el Ministerio de Pesquería (hoy, Ministerio de Cultura y Museo de la Nación, en la avenida Javier Prado Este, 1970). Todas estas arquitecturas, de gran escala y austeridad expresiva, se asocian inevitablemente al periodo de la Dictadura Militar y a los Gobiernos Revolucionarios de las Fuerzas Armadas, que se desarrollan a partir del golpe de estado del 3 de octubre de 1968, liderado por el general Juan Velasco Alvarado (1910-1977), y que conducen al Perú hasta el año 1979, momento en el que se restablece definitivamente la democracia.

\section{CONCLUSIÓN}

El panorama de la preservación del Patrimonio Arquitectónico y Urbano del Movimiento Moderno en América Latina es, como se ha visto, muy variado y prometedor. Sin embargo, la insólita abundancia y el precario estado de conservación de buena parte de este legado arquitectónico del siglo XX, comprometen gravemente la tarea que las instituciones de tutela y las iniciativas preservadoras deberán afrontar con decisión en las próximas décadas. La importante exposición sobre la arquitectura latinoamericana del siglo XX que se ha celebrado entre el 27 de marzo y el 15 de julio del año 2015 en el MoMA (Latin America in Construction: Architecture 1955-1980), ha marcado un hito en el interés internacional por el patrimonio moderno en América y, a buen seguro, va a contribuir a dirigir las miradas de los especialistas y de numerosos interesados hacia los muchos retos y oportunidades a los que nos enfrentamos para su conveniente conservación y su adecuado manejo y tutela.

En este contexto, el importante legado arquitectónico moderno que conserva la ciudad de Lima nos muestra con meridiana claridad las amenazas a las cuales se expone un patrimonio muy valioso pero todavía poco estudiado y quizá aún escasamente reconocido por sectores muy amplios de la sociedad. Los problemas que se pueden constatar como consecuencia del desequilibrio del mercado inmobiliario (resultado del fortísimo crecimiento económico que ha experimentado el país en los últimos años) y, sobre todo, la difícil situación en la que se encuentra el Centro Histórico de Lima, seriamente 
deteriorado social y económicamente durante las décadas de los setenta y ochenta, y que, a pesar de haber sido declarado Patrimonio de la Humanidad a principios de los noventa (1991), se encuentra todavía inmerso en un complejo e inconcluso proceso de rehabilitación urbana, nos permiten señalar la situación especialmente crítica y los riesgos a los cuales se enfrenta este extraordinario legado arquitectónico de la modernidad en el Perú.

\section{REFERENCIAS}

Bonilla di Tolla, E. (dir.) (2009). Guía de arquitectura y paisaje de Lima y El Callao. Lima/Sevilla: Universidad Ricardo Palma/Junta de Andalucía/AECID.

Castedo, L. (1970). Historia del arte y de la arquitectura latinoamericana. Barcelona: Editorial Pomaire.

Cruchaga, M. (2004). Fernando Belaunde Terry. El Arquitecto Peruano. Versión digital (www.elarquitectoperuano.com).

Gutiérrez, R. (2002). Arquitectura y urbanismo en Iberoamérica (1. a ed., 1984). Madrid: Ediciones Cátedra.

Harboe, T.G. (2004). United States architecture of the $19^{\text {th }}$ and $20^{\text {th }}$ centuries. En La representatividad en la Lista del Patrimonio Mundial, memorias. México: Instituto Nacional de Antropología e Historia / Icomos.

Henket, H.-J. \& Jonge, W. de (2010). A restoration concept for Modern Movement architecture. En P. Meurs y M.-T. van Thoor (eds.), Sanatorium Zonnestraal. History and restoration of a modern monument (pp. 179-201). Rotterdam: NAi Publishers.

ISC20C Icomos. (2011). Madrid Document.Approaches for the Conservation of the Twentieth Century Architectural Heritage [Documento de Madrid. Criterios de conservación del Patrimonio Arquitectónico del siglo XX ]. Madrid: Icomos.

Moreno de Barreda, F. (dir.) (1999). El patrimonio cultural en el Consejo de Europa. Textos, conceptos y concordancias. Madrid: Hispania Nostra/Boletín Oficial del Estado. 
Rivera, D. (2014). El patrimonio arquitectónico del Movimiento Moderno en Hispanoamérica. Cuadernos Hispanoamericanos, 766, 47-62. Madrid: Ministerio de Asuntos Exteriores y Cooperación/Agencia Española de Cooperación Internacional para el Desarrollo (AECID).

Vela Cossío, F. (2014). El futuro de la ciudad histórica en el Perú. RITA. Revista Indexada de Textos Académicos, 2, 44-45. Madrid: Red Fundamentos. 